\title{
The Diagnosis, Treatment, Prognosis and Molecular Pathology of Borderline Ovarian Tumors: Current Status and Perspectives
}

This article was published in the following Dove Press journal: Cancer Management and Research

Yu Sun

Juan Xu (D)

Xuemei Jia (iD

Department of Gynecology, Women's Hospital of Nanjing Medical University (Nanjing Maternity and Child Health Care Hospital), Nanjing 210004, People's Republic of China
Correspondence: Xuemei Jia; Juan Xu Tel +862552226162

Fax +862584460507

Email xmjia@njmu.edu.cn;

xujuannj@njmu.edu.cn

\begin{abstract}
Borderline ovarian tumors (BOTs) are a type of low malignant potential tumor that is typically associated with better outcomes than ovarian cancer. Indeed, its 10-year survival rate is as high as $95 \%$. However, there is a small subset of patients who experience relapse and eventually die. It has been shown that the prognosis of BOTs was based on pathological diagnosis, the age at diagnosis, pre-operative carbohydrate antigen 125 level, invasive implants, and micropapillary patterns. Now the molecular-targeted therapy and molecular-genetic diagnosis have developed into a form of precision medicine. Recent studies on extensive molecular characterizations and molecular pathological mechanisms of BOTs have helped us understand the genomic landscapes of BOTs, and therefore BOTs could be reclassified into biologically and clinically more accurate and effective subtypes. The purpose of this review is to summarize current status for the diagnosis and treatment of BOTs and to describe the research progress on molecular pathologies, with a goal of providing a theoretical perspective for the diagnosis and treatment of BOTs.
\end{abstract}

Keywords: borderline ovarian tumor, diagnosis, prognosis, molecular characterization

\section{Introduction}

In 1929, Taylor first proposed the concept of a borderline ovarian tumor, which was called a "semi-malignant ovarian tumor" at the time. In 1971, the International Federation of Obstetrics and Gynecology (FIGO) identified borderline ovarian tumors as a "low-grade malignant tumor" completely different from ovarian cancer. In the World Health Organization (WHO) classification of female genital tumors in 2014, the word "low-grade malignant tumor" was replaced by "borderline tumor" or "atypical proliferative tumor". 1

Borderline ovarian tumors (BOTs) account for $15 \%$ of epithelial ovarian tumors. $^{2}$ Depending on the type of tissue that is undergoing aberrant growth, BOTs can be divided into mucinous borderline ovarian tumors (MBOTs), serous borderline ovarian tumors (SBOTs), endometrial borderline tumors, clear cell borderline tumors, brenner borderline tumors, and others. ${ }^{3}$ In a cohort study in Denmark, MBOTs accounted for 50\% of BOTs, and SBOTs accounted for $44 \%$ of cases. ${ }^{4}$ Of note, the relative portion of BOTs that are MBOTs in Asia is $75.2 \%$, which is different from other continents. ${ }^{5}$

Compared with ovarian cancer, the vast majority of BOT is often limited to one or both sides of the ovary. Impressively, $75 \%$ of BOT is diagnosed at stage I, 
resulting in a good prognosis and a 10-year survival rate of about $95 \%{ }^{6}$ However, a small fraction of patients still experience recurrence or transformation into low-grade serous ovarian carcinoma (LGSOC), and the transformation was concealed, and LGSOC have been shown to respond poorly to platinum chemotherapy. ${ }^{7}$ Therefore, identifying the risk factors for invasive recurrence and clinical nonresponse are key to ensuring the successful treatment of BOT. ${ }^{8}$ The primary method of treatment of BOTs is surgery. The choice of surgery should be evaluated according to patients' age, fertility requirements, pathological stage, and pathological types. ${ }^{9}$ Because of the poor response of BOTs to chemotherapy, adjuvant chemotherapy is generally not recommended. ${ }^{10}$

In this work, we will discuss the diagnosis, treatment, prognosis, and current understandings of the molecular pathology of two common types of BOT.

\section{Diagnosis and Treatment Diagnosis}

Whereas the preoperative diagnosis of BOTs is difficult, a speculative diagnosis can be made according to clinical manifestations, tumor markers, and imaging examination. However, the final diagnosis needs to be supported by a pathological diagnosis encompassing the unusual degree of epithelial cell proliferation, and the existence of microinvasion. ${ }^{11,12}$

Almost $30 \%$ of patients with BOTs have no prior symptoms prior to diagnosis, and about $50-60 \%$ of patients have non-specific symptoms such as abdominal pain, abdominal distention, nonspecific vaginal bleeding, and sexual discomfort. ${ }^{13}$ In a study of 151 women with BOTs, $84 \%$ had these non-specific symptoms before diagnosis, and the average duration of symptoms in these patients was 6 months. ${ }^{14}$
Transvaginal ultrasound (TVUS), magnetic resonance imaging (MRI), and computed tomography (CT) are indispensable methods to assist in the presumptive diagnosis of BOTs. In a systematic review and meta-analysis of imaging tools for the diagnosis of BOTs, their sensitivites and specificities are $77.0 \%$ and $83.0 \%$ (TVUS), $85 \%$ and $74 \%$ (MRI), respectively. ${ }^{15}$ Ultrasound imaging had a certain value for the preoperative diagnosis of BOTs. ${ }^{16-18}$ However, recent reports have suggested that the preoperative diagnosis of BOTs is only with an accuracy of $69 \% .{ }^{19}$ Due to the absence of typical morphological features in BOTs, it is hard to distinguish BOTs from benign or malignant ovarian tumors. ${ }^{20,21}$ The value of CT and MRI features in differentiating BOTs from malignant tumors was relatively limited because of solid components size and septations' thickness. ${ }^{22,23}$

In a study of 266 patients from South Korea, when compared with a single tumor marker, such as ultrasound, menopausal state, carbohydrate antigen 125 (CA125), human epididymis protein 4 (HE4) and carbohydrate antigen 19-9 (CA19-9), the risk algorithm for ovarian cancer (ROMA, combined CA125, HE4 and Menopausal state) was found to be the best way to distinguish malignant and borderline tumors from benign tumors. ${ }^{24}$ While other studies indicated that the malignant tumor risk index (RMI, combined CA125, ultrasound and Menopausal state) is the best prediction method for distinguishing between borderline and benign ovarian tumors (Table 1). ${ }^{17}$ When the cutoff value of RMI1, RMI $2^{18}$ and RMI ${ }^{19}$ is 200 , the sensitivities are $80 \%, 90 \%$, $80 \%$, respectively, and the specificities are $86.4 \%, 82.6 \%$, and $86.4 \%$, respectively. At the cutoff value of 450 , RMI 4 has a sensitivity of $86.8 \%$ and a specificity of $91.0 \%{ }^{20}$

\section{Treatment}

Patients with any stage of BOT should undergo surgery. It is recommended that fertility-preserving patients should take

Table I Different Algorithms of Malignant Tumor Risk Index (RMI)

\begin{tabular}{|c|c|c|c|c|c|}
\hline & Formula & Ultra Sound Score (U) & Menopausal Status (M) & CAI 25 & $\begin{array}{l}\text { Tumor Size } \\
\text { (S) }\end{array}$ \\
\hline $\mathrm{RMII}^{79}$ & $\mathrm{U} \times \mathrm{M} \times \mathrm{CA} 125$ & $\begin{array}{l}\text { Score }=0, U=0 ; \text { Score }=I, U=1 ; \\
\text { Score } \geq 2, U=3\end{array}$ & $\begin{array}{l}\text { Premenopause } M=I ; \\
\text { Postmenopause, } M=3\end{array}$ & \multirow[t]{4}{*}{$\begin{array}{l}\text { Actual measured } \\
\text { value }\end{array}$} & - \\
\hline $\mathrm{RMI}^{80}$ & $\mathrm{U} \times \mathrm{M} \times \mathrm{CA} 125$ & Score $=0$ or $\mathrm{I}, \mathrm{U}=1$; Score $\geq 2, \mathrm{U}=4$ & $\begin{array}{l}\text { Premenopause } M=1 ; \\
\text { Postmenopause, } M=4\end{array}$ & & - \\
\hline $\mathrm{RMI} 3^{81}$ & $\mathrm{U} \times \mathrm{M} \times \mathrm{CA} / 25$ & Score $=0$ or $\mathrm{I}, \mathrm{U}=1$; Score $\geq 2, \mathrm{U}=3$ & $\begin{array}{l}\text { Premenopause } M=I ; \\
\text { Postmenopause } M=3\end{array}$ & & - \\
\hline $\mathrm{RMI}^{82}$ & $\mathrm{U} \times \mathrm{M} \times \mathrm{S} \times \mathrm{CAI} 25$ & Score $=0$ or $\mathrm{I}, \mathrm{U}=1$; Score $\geq 2, \mathrm{U}=4$ & $\begin{array}{l}\text { Premenopause } M=1 ; \\
\text { Postmenopause } M=4\end{array}$ & & $\begin{array}{l}<7 \mathrm{~cm}, \mathrm{~S}=1 \\
>7 \mathrm{~cm}, \mathrm{~S}=2\end{array}$ \\
\hline
\end{tabular}


unilateral or bilateral salpingo-oophorectomy. ${ }^{25}$ For patients without fertility requirements, total hysterectomy and bilateral salpingo-oophorectomy are recommended. ${ }^{7}$ Patients with metastases should be treated with maximal resection of the tumor. Laparoscopic surgery and open surgery showed similar recurrence rates and 10-year disease-free survival rate for BOTs. ${ }^{26}$ The laparoscopic surgery showed more favorable surgical outcomes including shorter operative time, shorter hospital stays, less blood loss, less transfusion requirement, sooner recovery of bowel movement, and fewer perioperative complications. ${ }^{27,28}$ The role of adjuvant chemotherapy for BOTs is still controversial. In early series, adjuvant chemotherapy showed beneficial effects in patients with advanced-stage, ${ }^{29}$ but in a prospective Gynecologic Oncology Group Study, Sutton et $\mathrm{al}^{30}$ noted that cisplatinbased chemotherapy had no effect on overall survival. And in a retrospective study of 80 patients with FIGO stage II-IV BOTs, Shih et $\mathrm{al}^{31}$ reported that there are no difference in 3 -year progression-free survival between patients who had received adjuvant chemotherapy or not.

It has been shown that the human cancer cell lines (extracted from "Cancer Cell Line Encyclopedia (CCLE)" database $^{32}$ and categorized based on their KRAS mutation status) with the KRAS G12V mutation was more sensitive to AZD6244 (selumetinib) than cells with wild-type KRAS. $^{33}$ A small-scale study showed that 2 SBOTs with the G12V mutation had development into LGSOC, and responded better to selumetinib. ${ }^{33}$ This study confirmed that research on the molecular pathology of disease can critically inform the clinical management of BOT.

\section{Recurrence and Prognosis}

Although the prognosis of most BOTs is good, there are still a few patients who will relapse and eventually die. According to a retrospective survey conducted by the Sloan Kettering Cancer Center in the United States, the age at the time of diagnosis, preoperative CA125 level, invasive implants, and micropapillary patterns are clinical factors that predict the risk of recurrence of BOTs. ${ }^{34}$ Additionally, higher stage at diagnosis, the use of BOT surgical method, and a history of pelvic inflammation are also clinical factors for the recurrence of BOTs. ${ }^{35,36}$

\section{Peritoneal Implants}

In the 1970s and 1980s, peritoneal implantation was widely used as a prognostic indicator. Implants were classified as invasive implants or non-invasive implants according to the morphology under the microscope. ${ }^{37}$ At that time, invasive implants and non-invasive implants were the most important prognostic indicators. ${ }^{38}$ After 7.4 years of follow-up, the survival rate of patients with non-invasive peritoneal implants was $95.3 \%$, while that of patients with invasive peritoneal implants was $66 \%$. Invasive implantation was indicative of relatively poor outcomes. $^{31,38}$ It is generally believed that the mortality of SBOTs patients is typically attributable to death due to non-ovarian tumor diseases. ${ }^{39}$ There is still a considerable controversy on how to treat SBOTs because of the difficulty in distinguishing non-invasive implants and invasive implants. $^{39}$ In one study, McKinney et al pathologists independently evaluated 8 morphological characteristics of peritoneal and/or lymph node implants in 181 patients with high-grade serous borderline tumors. These results showed that low-power destructive tissue invasion was the best predictor of poor prognosis. ${ }^{40}$

\section{Operation Methods}

Based on a multivariate analysis of 127 BOTs, fertilitypreserving surgery is an independent prognostic factor of decreased 5-year recurrence-free survival (RFS). Indeed, conservative surgery is closely related to recurrence. ${ }^{41}$ Vasconcelos and de Sousa Mendes ${ }^{42}$ analyzed 39 studies using the PubMed database and Cochrane Library, including a total of 5105 women that underwent conservative surgery (2624 serous, 2120 mucinous, and 361 other types of BOT). They found that unilateral SBOT had a higher recurrence rate after ovarian tumor resection, but that there was no significant difference in overall survival rate across tumor types.

\section{Micropapillary Pattern}

A micropapillary pattern has often been reported to be associated with invasive implants, bilateral ovarian involvement, and lymph node metastasis. ${ }^{43-46}$ However, the use of micropapillary pattern as an independent factor to predict BOTs is controversial in the field. ${ }^{46,47}$ Park et al $^{46}$ and Chang et $\mathrm{al}^{47}$ pointed out that the micropapillary pattern is a poor prognostic factor for BOTs because it is closely associated with microinvasion, lymph node metastasis, and peritoneal implants, but they did not report the micropapillary pattern as an independent risk factor for death. In contrast, Burks, Shih, Sozen et al suggested that the micropapillary pattern was an independent risk factor associated with recurrence of BOTs. ${ }^{34,43,48}$

In general, it seems likely that the micropapillary pattern, invasive peritoneal implants, and the method of 
surgery can affect the prognosis of patients with BOT; however, follow-up studies are needed to confirm whether these factors independently or collectively affect BOT recurrence and prognosis. ${ }^{49}$

\section{Molecular Pathology}

The development of molecular biology has greatly promoted our understanding of the occurrence, and progression of BOTs. As a low malignant potential ovarian epithelial tumor, peritoneal metastases are also observed in BOTs, but the peritoneal implantation in BOTs may subside by itself, which is totally different from malignant ovarian tumor, and responsible for the high survival rate of BOTs. However, the driver of metastatic tumor regression or malignant progression in BOTs is still unknown. Here, we summarized the research progress of the molecular characteristics of BOTs and compared the difference between BOTs and malignant ovarian tumors, with the aim to find the driver genes for the malignant transformation potential or metastatic tumor regression.

\section{Molecular Profiling of Borderline Ovarian Tumors}

A variety of studies discussed the molecular characteristic of BOTs and their relationship with malignant ovarian tumor and benign ovarian tumor. As shown in Table 2, according to the molecular characteristics, some experts

Table 2 Molecular Profiling of BOTs

\begin{tabular}{|l|l|l|}
\hline Authors & Methods & Results \\
\hline $\begin{array}{l}\text { Waldemarson } \\
\text { t }^{50}\end{array}$ & $\begin{array}{l}\text { iTRAQ Screen } \\
\text { MRM Analysis } \\
\text { ROC-Curve } \\
\text { Analysis }\end{array}$ & $\begin{array}{l}\text { ROC area=I, benign vs } \\
\text { malignant } \\
\text { ROC area=0.97, benign vs } \\
\text { borderline } \\
\text { ROC area=0.85, borderline } \\
\text { vs malignant }\end{array}$ \\
\hline $\begin{array}{l}\text { Bengtsson } \\
\text { et al }\end{array}$ & $\begin{array}{l}\text { 2D DIGE Analysis } \\
\text { ROC-Curve } \\
\text { Analysis }\end{array}$ & $\begin{array}{l}\text { ROC area=I, benign vs } \\
\text { malignant } \\
\text { ROC area }=0.98, \text { benign vs } \\
\text { borderline } \\
\text { ROC area }=0.92, \text { borderline } \\
\text { vs malignant }\end{array}$ \\
\hline Alaiya et al & $\begin{array}{l}\text { Hierarchical cluster } \\
\text { Analysis }\end{array}$ & $\begin{array}{l}\text { BOTs close to benign } \\
\text { tumors }\end{array}$ \\
\hline Curry et al & $\begin{array}{l}\text { Gene Expression } \\
\text { Microarrays } \\
\text { Hierarchical cluster } \\
\text { Analysis }\end{array}$ & $\begin{array}{l}\text { Benign-like BOTs } \\
\text { Malignant-like BOTs }\end{array}$ \\
\hline
\end{tabular}

believed that BOTs may close to benign ovarian tumors, while other experts suggested that BOTs may close to malignant ovarian tumors.

Waldemarson et al ${ }^{50}$ carried out isobaric tags for relative and absolute quantitation (iTRAQ) technology to present a shotgun quantitative proteomic screen of 51 ovarian tissue samples ( 7 normal cases, 4 benign cases, 16 borderline cases and 24 malignant cases) and further confirmed selected candidate proteins from the shotgun screen using multiple reaction monitoring (MRM) analysis. Receiver Operating Characteristic (ROC)-area analysis using MRM profile showed that the malignant and benign tumors were perfectly separated with a ROC-area of 1 while the ROC analysis placed BOTs closer to the malignant than the benign tumors (ROC area $=0.97$, borderline vs benign, ROC area $=0.85$, borderline vs malignant). Further, Bengtsson et $\mathrm{al}^{51}$ used two-dimension difference gel electrophoresis (2D-DIGE) analysis to study 64 epithelial ovarian tissues ( 8 normal tissues, 12 benign tumor tissues, 17 borderline tumor tissues, 27 malignant tumor tissues). ROC-area analysis based on statistical analysis of gel images also showed that BOTs were closer to the malignant tumors than the benign tumors ( $\mathrm{ROC}$ area $=0.98$, borderline vs benign, ROC area $=0.92$, borderline vs malignant). However, in Alaiya et al study, 40 of ovarian tumor cases (including 10 BOTs) were classified by hierarchical cluster analysis based on the expression of proteins analyzed by 2D-DIGE, and it was found that BOTs were more closely related to benign tumors than to malignant tumors. ${ }^{52}$ Curry et $\mathrm{al}^{53}$ used Affymetrix HGU133 plus2 GeneChip microarrays to study the gene expression profile of 3 LGSOCs, 13 SBOTs and 8 serous ovarian cystadenomas. Unsupervised clustering revealed that the benign and malignant tumors were clearly separated, whereas BOTs showed two different molecular subtypes: benign-like group and malignant-like group.

\section{Gene Expression and Pathways Alteration in BOTs}

Although only few studies have focused on the molecular mechanism of malignant transformation of BOTs, the limited studies still greatly promote our understanding of the biological pathology of BOTs and provide important information for the prognosis and recurrence risk prediction of BOTs (Table 3).

It has been reported that $88 \%$ of SBOTs contain BRAF or KRAS mutations and that $86 \%$ of cystadenoma epithelial cells adjacent to SBOTs harbor the same mutations, indicating that mutations in BRAF or KRAS are very early 
Table 3 The Mutation or Abnormal Expression Frequency of BOTs-Related Genes

\begin{tabular}{|c|c|c|c|}
\hline & Gene & SBOTs & MBOTs \\
\hline MAPK Pathway Activation ${ }^{56-58,63}$ & $\begin{array}{l}\text { BRAF mutation } \\
\text { KRAS mutation } \\
\text { ERBB2 mutation/Amplification } \\
\text { Claudin-I overexpression }\end{array}$ & $\begin{array}{l}23-48 \% \\
17-39.5 \% \\
6 \% \\
26.3 \%\end{array}$ & $\begin{array}{l}0.0 \% \\
92.3 \% \\
3.8 \% / 11.5 \% \\
\text { NA }\end{array}$ \\
\hline PI3K/AKT Pathway Activation 57,64 & $\begin{array}{l}\text { P53 mutation/Overexpression } \\
\text { CDKNA2 mutation } \\
\text { PTEN mutation } \\
\text { PIK3CA mutation }\end{array}$ & $\begin{array}{l}\text { Overexpression } \\
\text { NA } \\
\text { NA } \\
\text { NA }\end{array}$ & $\begin{array}{l}11.5 \% \\
19.2 \% \\
3.8 \% \\
15.4 \%\end{array}$ \\
\hline Hedgehog Pathway Activation ${ }^{74}$ & $\begin{array}{l}\text { SHH positive expression } \\
\text { IHH positive expression } \\
\text { DHH positive expression } \\
\text { PTCH positive expression } \\
\text { SMO positive expression } \\
\text { GLII positive expression }\end{array}$ & $\begin{array}{l}42.8 \% \\
14.3 \% \\
71.4 \% \\
71.4 \% \\
42.8 \% \\
57.1 \%\end{array}$ & $\begin{array}{l}0.0 \% \\
0.0 \% \\
12.5 \% \\
62.5 \% \\
62.5 \% \\
37.5 \%\end{array}$ \\
\hline $\begin{array}{l}\text { Clarification of Mucinous Subtype \& } \\
\text { Indicators for the Malignant Features }\end{array}$ & $\begin{array}{l}\text { TFF3 strong expression } \\
\text { IMP3 strong expression } \\
\text { I8 }\end{array}$ & $\begin{array}{l}0.0 \% \\
8.3 \%\end{array}$ & $\begin{array}{l}61.4 \% \\
42.2 \%\end{array}$ \\
\hline
\end{tabular}

events in the development of SBOTs. ${ }^{54,55}$ In addition, the ERBB2 mutation was found in $6 \%$ of SBOTs. ${ }^{56}$ In MBOTs, mutations of KRAS (92.3\%), p53 (11.5\%), CDKN2A (19.2\%), PIK3CA (15.4\%), PTEN (3.8\%), ERBB2 (3.8\%) and amplification of ERBB2 (11.5\%) have been reported. Besides, 7.7\% of MBOTs showed ERBB2 amplification and KRAS mutation at the same time. $^{57}$ The amplification region of ERBB2 contains KRAS mutations, indicating that these mutations occur in the same cell line and that the mutation frequency of the KRAS allele is consistent in the amplification and nonamplification region of ERBB2. This suggests that the mutation occurred before the amplification event. ${ }^{57}$ Moreover, mutations in KRAS, BRAF, and ERBB2 are mutually exclusive; mutations in any one of these three genes will activate the mitogen-activated protein kinase (MAPK) signaling pathway, leading to uncontrolled cell proliferation. $^{56}$ The incidence of KRAS mutation in SBOTs (17-39.5\%) was similar to that in LGSOC (19$54.5 \%$ ). On the contrary, the incidence of BRAF mutation in SBOT and LGSOC was $23-48 \%$ and $0-33 \%$, respectively. ${ }^{58}$ Therefore, benign ovarian serous tumors may progress to SBOTs due to BRAF mutations, but such mutations rarely participate in the transformation to LGSOC. ${ }^{59}$ SBOTs with BRAF mutations are associated with cell senescence and up-regulation of tumor suppressor genes. ${ }^{60}$ KRAS mutations are common $(>70 \%)$ in recurrent LGSOC, while BRAF mutations are rare, which suggested that recurrent LGSOC could arise from SBOTs having KRAS mutations or other genetic changes but not BRAF mutations. ${ }^{33}$

The vast majority of peritoneal implants, both noninvasive and invasive, harbored the same KRAS or BRAF mutations, presented in the associated SBOT. ${ }^{61}$ Compared with non-invasive implants, patients with invasive extra-ovarian peritoneal implants had a higher stage of disease, a higher recurrence rate and a shorter survival period. ${ }^{62}$ KRAS mutations are common in SBOTs with invasive implants and recurrent low-grade serous ovarian cancer, but the BRAF V600E mutation is not common. $^{33,62}$ Therefore, regardless of the histological subtypes of implants, KRAS mutations are an important prognostic indicator of tumor recurrence and decreased disease-specific survival rate. ${ }^{62}$ In addition, El-Balat et al found that Claudin-1 is related to predictors of poor prognosis (eg, peritoneal implantation and micropapillary pattern), and the authors hypothesized that the overexpression of Claudin-1 may be related to the activation of the mitogen-activated protein kinase (MAPK) signaling pathway. ${ }^{63}$

Different from inhibited p53 signaling in high-grade serous ovarian cancer (HGSOC), overexpressed p53 and changes in genes associated with the p53 pathway were observed in SBOTs. ${ }^{64}$ Cheng et al ${ }^{65}$ confirmed that SBOTs contained wild-type p53 by sequencing. Besides, they found that inhibition of p53 can significantly increase the invasiveness of SBOT cells. By activating the PI3K/AKT 
pathway, p53 reduces the expression of E-cadherin and regulates the transformation of SBOT cells from noninvasive ovarian cancer to invasive ovarian cancer. This result not only indicated that the development of SBOTs to invasive LGSOC involves a reduction in of p53 signal transduction but also suggested that p53 can inhibit the epithelial-mesenchymal transformation (EMT) process in SBOTs cells and thus the transformation to invasive ovarian cancer.

El-Balat et al ${ }^{66}$ further analyzed the expression of Trefoil factor-3 (TFF3) in 137 cases of BOT by immunohistochemistry and studied its relationship with histopathological characteristics. They found that the strong expression rate of TFF3 was $21.9 \%$ and there was no strong TFF3 expression in SBOTs and endometrial borderline tumors. On the other hand, TFF3 was highly expressed in $61.4 \%$ of MBOT $(P<0.001)$, suggesting that TFF3 potentially plays a role in MBOTs. ${ }^{66}$ In addition, insulin-like growth factor II mRNA binding protein 3 (IMP3) is considered a prognostic marker of ovarian clear cell carcinoma. $^{67}$ El-Balat et al $^{68}$ analyzed the expression of IMP3 in 140 cases of BOT in a cohort and found that the expression of IMP3 was not related to the age of patients, FIGO stage, microinvasion, or the presence of implants, but was related to the mucinous subtype of BOTs (mucinous vs other subtypes, $42.2 \%$ vs $9.5 \%, P<0.001)$. In MBOT, the expression of IMP3 was correlated with the presence of carcinoma in situ, but not with other subtypes $(P=0.021)$. The expression of IMP3 in BOT is associated with mucinous subtype, which can be used as an early indicator of malignant feature. The high specific expression of TFF3 and IMP3 in MBOT may help elucidate the relationship between mucus subtypes and malignant transformation.

The hedgehog (Hh) signal pathway plays a critical role in ovarian tumorigenesis and most authors frequently examined the 6 components of the pathway: Sonic hedgehog (SHH), Indian hedgehog $(\mathrm{IHH})$ and Desert hedgehog $(\mathrm{DHH})$, the Hh-ligand receptor Patched 1 (PTCH1), the transmembrane protein Smoothened (SMO) and the glioma-associated oncogene homolog 1 (GLI1). ${ }^{6-72}$ Recent data showed that the expression of GLI1 correlated with poor prognosis of advanced serous ovarian cancer. ${ }^{73}$ Chen et $\mathrm{al}^{74}$ used immunohistochemical staining to detect the immunoreactivity of Hh pathway proteins in 86 cases of primary ovarian epithelial tumors (14 benign tumors, 15 BOTs, 57 cancers) and 6 normal ovarian epithelial cells. The extent of immunoreactivity of Hh pathway proteins in BOTs was between benign and malignant tumors and the immunostaining score of GLI1 was significantly increased in carcinomas compared to those in BOTs. ${ }^{74}$ However, Ozretic et al ${ }^{75}$ detected the expression of molecules related to Hh pathway in 41 samples (16 cases of malignant epithelial ovarian cancer, 7 cases of BOT, 9 cases of normal ovarian tissue and 9 cases of fallopian tube tissue) by real-time quantitative PCR. This study showed that GLI1 was highly expressed in BOTs than to ovarian cancer. ${ }^{75}$ Song et $\mathrm{al}^{76}$ using immunofluorescent staining to evaluate the expression of genes in Hh pathway in 193 cases of ovarian epithelial tumors (including 147 cases of malignant epithelial ovarian cancer, 30 cases of BOT, 16 cases of benign ovarian epithelial tumors) and 11 cases of normal ovarian epithelial tissues. Compared with benign ovarian epithelial tumor, GLI1 was highly expressed in BOT but there was no significant difference in expression of GLI1 in BOTs versus ovarian cancer. ${ }^{76}$ Survivin has recently been described as a new target of this pathway. ${ }^{77}$ In a study by Kanter et al, ${ }^{77}$ the expression of Survivin in mucinous ovarian tumors was found in $88.1 \%$ of malignant tumors and $18.2 \%$ of borderline tumors, respectively, suggesting that Survivin was positively correlated with malignant mucinous tumors.

\section{Discussion}

BOTs are typically diagnosed earlier in development and thus have a higher survival rate. However, they can spread to the peritoneum and eventually to lymph nodes, similar to cancer, so it is important to identify the risk factors that predict invasive recurrence or disease-related death. Pathologists play a key role in assessing the borderline character of ovarian tumors and in determining the likelihood of aggressive recurrence and potential death from disease. In addition, recent molecular research has proved to aid our understanding of the pathogenesis of disease and invasive recurrence of BOT; however, significant further work is required to clarify the relationship between ovarian tumors and extra-ovarian diseases, to determine prognosis indicators, and to develop methods for targeted treatment. Varying definitions of BOTs may arise due to a relatively small number of available tumor samples or the use of different analysis methods. Ideally, more BOTs samples should be characterized at the genetic level in order to potentially identify gene subtypes for further study. KRAS and BRAF mutations represent the early events in the development of SBOTs, but BRAF mutations seem to have a protective effect on the progression of LGSOC, and KRAS mutations usually occur in SBOTs with LGSOC recurrence. Further, p53-mediated inhibition of PI3K/AKT signaling may be a key factor 
regulating the progression of SBOTs to an invasive phenotype. The Ras/MAPK and PI3K/AKT pathways regulate cell apoptosis, growth and expression of a diverse set of genes, critically impacting cell membrane receptor signal transmission. The interaction between the Ras/ MAPK and PI3K/AKT pathway has been demonstrated in many cell types and experiments. ${ }^{78}$ Therefore, the molecular implications of interactions between the Ras/ MAPK pathway and PI3K/AKT pathway in the transformation of SBOT to invasive and recurrent LGSOC still needs to be explored. Various publications have come to differing results of the expression of components of the hedgehog signal pathway in BOTs. GLI1 has been shown to be a risk factor in the development of ovarian cancer. ${ }^{73}$ Due to people using different methods to monitor GLI1 expression level, there is not a clear consensus on its gene expression level and protein expression level in BOTs and ovarian cancer. Hence, further studies are required to clarify the function of GLI1 in BOTs. The incidence of MBOT in Asia is higher than around the world, ${ }^{5}$ and the molecular mechanisms influencing the occurrence, development, and recurrence of MBOT remain to be elucidated.

\section{Funding}

This work was supported by the National Natural Science Foundation of China (grant numbers: 81602285 \& 81872126), Nanjing Medical Science and technique Development Foundation (No. JQX17009).

\section{Disclosure}

The authors report no conflicts of interest in this work.

\section{References}

1. Kurman R, Carcangiu ML, Herrington CS, Young RH. WHO Classification of Tumours of Female Reproductive Organs. 4th ed. Lyon: IARC Press; 2014.

2. Silverberg SG, Bell DA, Kurman RJ, et al. Borderline ovarian tumors: key points and workshop summary. Hum Pathol. 2004;35(8):910-917. doi:10.1016/j.humpath.2004.03.003

3. Hauptmann S, Friedrich K, Redline R, Avril S. Ovarian borderline tumors in the 2014 WHO classification: evolving concepts and diagnostic criteria. Virchows Arch. 2017;470(2):125-142. doi:10.1007/ s00428-016-2040-8

4. Hannibal CG, Huusom LD, Kjaerbye-Thygesen A, Tabor A, Kjaer SK. Trends in incidence of borderline ovarian tumors in Denmark 1978-2006. Acta Obstet Gynecol Scand. 2011;90(4):305-312. doi:10.1111/j.1600-0412.2010.01060.x

5. Yokoyama Y, Moriya T, Takano T, et al. Clinical outcome and risk factors for recurrence in borderline ovarian tumours. $\mathrm{Br} J$ Cancer. 2006;94(11):1586-1591. doi:10.1038/sj.bjc.6603139
6. Sobiczewski P, Kupryjanczyk J, Michalski W, Śpiewankiewicz B. The evaluation of risk factors associated with relapse and recurrence of borderline ovarian tumors with long-term follow-up. Int $J$ Gynecol Cancer. 2016;26(6):1053-1061. doi:10.1097/IGC.0000000000000722

7. Berek JS, Kehoe ST, Kumar L, Friedlander M. Cancer of the ovary, fallopian tube, and peritoneum. Int J Gynaecol Obstet. 2018;143 (Suppl 2):59-78. doi:10.1002/ijgo.12614

8. Morice P, Uzan C, Fauvet R, Gouy S, Duvillard P, Darai E. Borderline ovarian tumour: pathological diagnostic dilemma and risk factors for invasive or lethal recurrence. Lancet Oncol. 2012;13 (3):e103-e115. doi:10.1016/S1470-2045(11)70288-1

9. Romeo M, Pons F, Barretina P, Radua J. Incomplete staging surgery as a major predictor of relapse of borderline ovarian tumor. World J Surg Oncol. 2013;11:13. doi:10.1186/1477-7819-11-13

10. Cadron I, Leunen K, Van Gorp T, Amant F, Neven P, Vergote I. Management of borderline ovarian neoplasms. J Clin Oncol. 2007;25 (20):2928-2937. doi:10.1200/JCO.2007.10.8076

11. Ushijima K, Kawano K, Tsuda N, et al. Epithelial borderline ovarian tumor: diagnosis and treatment strategy. Obstet Gynecol Sci. 2015;58 (3):183-187. doi:10.5468/ogs.2015.58.3.183

12. Link CJ, Reed E, Sarosy G, Kohn EC. Borderline ovarian tumors. Am J Med. 1996;101(2):217-225. doi:10.1016/S0002-9343(96)80079-9

13. Gershenson DM. Management of borderline ovarian tumours. Best Pract Res Clin Obstet Gynaecol. 2017;41:49-59. doi:10.1016/j. bpobgyn.2016.09.012

14. Vine MF, Ness RB, Calingaert B, Schildkraut JM, Berchuck A. Types and duration of symptoms prior to diagnosis of invasive or borderline ovarian tumor. Gynecol Oncol. 2001;83(3). doi:10.1006/ gyno.2001.6411

15. Borrelli GM, de Mattos LA, Andres MP, Goncalves MO, Kho RM, Abrao MS. Role of imaging tools for the diagnosis of borderline ovarian tumors: a systematic review and meta-analysis. $J$ Minim Invasive Gynecol. 2017;24(3):353-363. doi:10.1016/j.jmig.2016.12.012

16. Timmerman D, Schwarzler P, Collins WP, et al. Subjective assessment of adnexal masses with the use of ultrasonography: an analysis of interobserver variability and experience. Ultrasound Obstet Gynecol. 1999;13(1):11-16. doi:10.1046/j.1469-0705.1999.13010011.x

17. Valentin L. Prospective cross-validation of doppler ultrasound examination and gray-scale ultrasound imaging for discrimination of benign and malignant pelvic masses. Ultrasound Obstet Gynecol. 1999;14(4):273-283. doi:10.1046/j.1469-0705.1999.14040273.x

18. Valentin L, Hagen B, Tingulstad S, Eik-Nes S. Comparison of 'pattern recognition' and logistic regression models for discrimination between benign and malignant pelvic masses: a prospective cross validation. Ultrasound Obstet Gynecol. 2001;18(4):357-365. doi:10.1046/j.0960-7692.2001.00500.x

19. Yazbek J, Raju KS, Ben-Nagi J, Holland T, Hillaby K, Jurkovic D. Accuracy of ultrasound subjective 'pattern recognition' for the diagnosis of borderline ovarian tumors. Ultrasound Obstet Gynecol. 2007;29(5):489-495. doi:10.1002/uog.4002

20. Valentin L, Ameye L, Testa A, et al. Ultrasound characteristics of different types of adnexal malignancies. Gynecol Oncol. 2006;102 (1):41-48. doi:10.1016/j.ygyno.2005.11.015

21. Yazbek J, Ameye L, Timmerman D, et al. Use of ultrasound pattern recognition by expert operators to identify borderline ovarian tumors: a study of diagnostic performance and interobserver agreement. Ultrasound Obstet Gynecol. 2010;35(1):84-88. doi:10.1002/uog.7334

22. Yang S, Tang H, Xiao F, Zhu J, Hua T, Tang G. Differentiation of borderline tumors from type I ovarian epithelial cancers on CT and MR imaging. Abdom Radiol (NY). 2020. doi:10.1007/s00261-02002467-w

23. deSouza NM, O'Neill R, McIndoe GA, Dina R, Soutter WP. Borderline tumors of the ovary: CT and MRI features and tumor markers in differentiation from stage I disease. Am J Roentgenol. 2005;184(3):999-1003. doi:10.2214/ajr.184.3.01840999 
24. Shin KH, Kim HH, Kwon BS, Suh DS, Joo JK, Kim KH. Clinical usefulness of cancer antigen (CA) 125, human epididymis 4, and CA72-4 levels and risk of ovarian malignancy algorithm values for diagnosing ovarian tumors in korean patients with and without endometriosis. Ann Lab Med. 2020;40(1):40-47. doi:10.3343/ alm.2020.40.1.40

25. Sun H, Chen X, Zhu T, Liu N, Yu A, Wang S. Age-dependent difference in impact of fertility preserving surgery on disease-specific survival in women with stage I borderline ovarian tumors. J Ovarian Res. 2018;11(1):54.

26. Jung H, Park J, Kim D, et al. Comparison of laparoscopic and open surgery for patients with borderline ovarian tumors. Int $J$ Gynecol Cancer. 2018;28(9):1657-1663. doi:10.1097/IGC.0000000000001358

27. Song T, Kim MK, Jung YW, et al. Minimally invasive compared with open surgery in patients with borderline ovarian tumors. Gynecol Oncol. 2017;145(3):508-512. doi:10.1016/j.ygyno.2017.03.019

28. Odegaard E, Staff AC, Langebrekke A, Engh V, Onsrud M. Surgery of borderline tumors of the ovary: retrospective comparison of short-term outcome after laparoscopy or laparotomy. Acta Obstet Gynecol Scand. 2007;86(5):620-626. doi:10.1080/00016340701286934

29. Barakat RR, Benjamin I, Lewis JL Jr., Saigo PE, Curtin JP, Hoskins WJ. Platinum-based chemotherapy for advanced-stage serous ovarian carcinoma of low malignant potential. Gynecol Oncol. 1995;59(3):390-393. doi:10.1006/gyno.1995.9956

30. Sutton GP, Bundy BN, Omura GA, Yordan EL, Beecham JB, Bonfiglio T. Stage III ovarian tumors of low malignant potential treated with cisplatin combination therapy (a Gynecologic Oncology Group study). Gynecol Oncol. 1991;41(3):230-233. doi:10.1016/ 0090-8258(91)90314-U

31. Shih KK, Zhou QC, Aghajanian C, et al. Patterns of recurrence and role of adjuvant chemotherapy in stage II-IV serous ovarian borderline tumors. Gynecol Oncol. 2010;119(2):270-273. doi:10.1016/j. ygyno.2010.07.019

32. Barretina J, Caponigro G, Stransky N, et al. The cancer cell line encyclopedia enables predictive modelling of anticancer drug sensitivity. Nature. 2012;483(7391):603-607. doi:10.1038/ nature11003

33. Tsang YT, Deavers MT, Sun CC, et al. KRAS (but not BRAF) mutations in ovarian serous borderline tumour are associated with recurrent low-grade serous carcinoma. J Pathol. 2013;231 (4):449-456. doi:10.1002/path.4252

34. Shih KK, Zhou Q, Huh J, et al. Risk factors for recurrence of ovarian borderline tumors. Gynecol Oncol. 2011;120(3):480-484. doi:10.1016/ j.ygyno.2010.11.016

35. Boyraz G, Salman MC, Gultekin M, et al. What is the impact of stromal microinvasion on oncologic outcomes in borderline ovarian tumors? A multicenter case-control study. Arch Gynecol Obstet. 2017;296(5):979-987. doi:10.1007/s00404-017-4496-4

36. Rasmussen CB, Kjaer SK, Albieri V, et al. Pelvic inflammatory disease and the risk of ovarian cancer and borderline ovarian tumors: a pooled analysis of 13 case-control studies. Am J Epidemiol. 2017;185(1):8-20. doi:10.1093/aje/kww161

37. Yoonessi M, Crickard K, Celik C, Yoonessi S. Borderline epithelial tumors of the ovary: ovarian intraepithelial neoplasia. Obstet Gynecol Surv. 1988;43(8):435-444. doi:10.1097/00006254-198808000-00001

38. Seidman JD, Kurman RJ. Ovarian serous borderline tumors: a critical review of the literature with emphasis on prognostic indicators. Hum Pathol. 2000;31(5):539-557. doi:10.1053/hp.2000.8048

39. Ie M S, Kurman RJ. Molecular pathogenesis of ovarian borderline tumors: new insights and old challenges. Clin Cancer Res. 2005;11 (20):7273-7279. doi:10.1158/1078-0432.CCR-05-0755

40. McKenney JK, Gilks CB, Kalloger S, Longacre TA. Classification of extraovarian implants in patients with ovarian serous borderline tumors (tumors of low malignant potential) based on clinical outcome. Am J Surg Pathol. 2016;40(9):1155-1164. doi:10.1097/ PAS.0000000000000692
41. Demirkiran F, Sal V, Bese T, et al. Risk factors for recurrence of borderline ovarian tumours: a tertiary centre experience. J Obstet Gynaecol. 2016;36(8):1036-1040. doi:10.1080/01443615.2016.1188276

42. Vasconcelos I, de Sousa Mendes M. Conservative surgery in ovarian borderline tumours: a meta-analysis with emphasis on recurrence risk. Eur J Cancer. 2015;51(5):620-631. doi:10.1016/j.ejca.2015.01.004

43. Burks RT, Sherman ME, Kurman RJ. Micropapillary serous carcinoma of the ovary. A distinctive low-grade carcinoma related to serous borderline tumors. Am J Surg Pathol. 1996;20(11):1319-1330. doi:10.1097/00000478-199611000-00003

44. Seidman JD, Kurman RJ. Subclassification of serous borderline tumors of the ovary into benign and malignant types. A clinicopathologic study of 65 advanced stage cases. Am J Surg Pathol. 1996;20(11):1331-1345. doi:10.1097/00000478-199611000-00004

45. Cusidó M, Fábregas R, Pere BS, Escayola C, Barri PN. Ovulation induction treatment and risk of borderline ovarian tumors. Gynecol Endocrinol. 2007;23(7):373-376. doi:10.1080/09513590701350341

46. Park JY, Kim DY, Kim JH, et al. Micropapillary pattern in serous borderline ovarian tumors: does it matter? Gynecol Oncol. 2011;123 (3):511-516. doi:10.1016/j.ygyno.2011.08.008

47. Chang SJ, Ryu HS, Chang KH, Yoo SC, JH Y. Prognostic significance of the micropapillary pattern in patients with serous borderline ovarian tumors. Acta Clin Croat. 2008;87(4):476-481.

48. Sozen H, Vatansever D, Topuz S, et al. Clinicopathological analysis of borderline ovarian tumours and risk factors related to recurrence: experience of single institution. J Obstet Gynaecol. 2018;39 (2):253-258. doi:10.1080/01443615.2018.1499076

49. Morrison J. Borderline ovarian tumours: balancing risks of recurrence over decades. BJOG. 2017;124(6):945. doi:10.1111/1471-0528.14598

50. Waldemarson S, Krogh M, Alaiya A, et al. Protein expression changes in ovarian cancer during the transition from benign to malignant. J Proteome Res. 2012;11(5):2876-2889. doi:10.1021/ pr201258q

51. Bengtsson S, Krogh M, Szigyarto CA, et al. Large-scale proteomics analysis of human ovarian cancer for biomarkers. J Proteome Res. 2007;6(4):1440-1450. doi:10.1021/pr060593y

52. Alaiya AA, Franzen B, Hagman A, et al. Molecular classification of borderline ovarian tumors using hierarchical cluster analysis of protein expression profiles. Int $J$ Cancer. 2002;98(6):895-899. doi:10.1002/ijc. 10288

53. Curry EWJ, Stronach EA, Rama NR, Wang YYP, Gabra H, ElBahrawy MA. Molecular subtypes of serous borderline ovarian tumor show distinct expression patterns of benign tumor and malignant tumor-associated signatures. Mod Pathol. 2013;27(3):433-442. doi:10.1038/modpathol.2013.130

54. Mayr D, Hirschmann A, Löhrs U, Diebold J. KRAS and BRAF mutations in ovarian tumors: a comprehensive study of invasive carcinomas, borderline tumors and extraovarian implants. Gynecol Oncol. 2006;103(1):883-887. doi:10.1016/j.ygyno.2006.05.029

55. Ho CL, Kurman RJ, Dehari R, Wang TL, IeM S. Mutations of BRAF and KRAS precede the development of ovarian serous borderline tumors. Cancer Res. 2004;64(19):6915-6918. doi:10.1158/00085472.CAN-04-2067

56. Anglesio MS, Arnold JM, George J, et al. Mutation of ERBB2 provides a novel alternative mechanism for the ubiquitous activation of RAS-MAPK in ovarian serous low malignant potential tumors. Mol Cancer Res. 2008;6(11):1678-1690. doi:10.1158/1541-7786. MCR-08-0193

57. Mackenzie R, Kommoss S, Winterhoff BJ, et al. Targeted deep sequencing of mucinous ovarian tumors reveals multiple overlapping RAS-pathway activating mutations in borderline and cancerous neoplasms. BMC Cancer. 2015;15:415-425. doi:10.1186/s12885015-1421-8

58. Malpica A, Wong KK. The molecular pathology of ovarian serous borderline tumors. Ann Oncol. 2016;27(1):i16-i19. doi:10.1093/ annonc/mdw089 
59. Wong KK, Tsang YT, Deavers MT, et al. BRAF mutation is rare in advanced-stage low-grade ovarian serous carcinomas. Am J Pathol. 2010;177(4):1611-1617. doi:10.2353/ajpath.2010.100212

60. Zeppernick F, Ardighieri L, Hannibal CG, et al. BRAF mutation is associated with a specific cell type with features suggestive of senescence in ovarian serous borderline (atypical proliferative) tumors. Am J Surg Pathol. 2014;38(12):1603-1611. doi:10.1097/PAS.0000000000000313

61. Ardighieri L, Zeppernick F, Hannibal CG, et al. Mutational analysis of BRAF and KRAS in ovarian serous borderline (atypical proliferative) tumours and associated peritoneal implants. J Pathol. 2014;232 (1):16-22. doi:10.1002/path.4293

62. Zuo T, Wong S, Buza N, Hui P. KRAS mutation of extraovarian implants of serous borderline tumor: prognostic indicator for adverse clinical outcome. Mod Pathol. 2018;31(2):350-357. doi:10.1038/ modpathol.2017.121

63. El-Balat A, Schmeil I, Gasimli K, et al. Claudin-1 is linked to presence of implants and micropapillary pattern in serous borderline epithelial tumours of the ovary. J Clin Pathol. 2018;71 (12):1060-1064. doi:10.1136/jclinpath-2018-205292

64. Bonome T, Lee JY, Park DC, et al. Expression profiling of serous low malignant potential, low-grade, and high-grade tumors of the ovary. Cancer Res. 2005;65(22):10602-10612. doi:10.1158/0008-5472.CAN05-2240

65. Cheng JC, Auersperg N, Leung PC. Inhibition of p53 induces invasion of serous borderline ovarian tumor cells by accentuating PI3K/Akt-mediated suppression of E-cadherin. Oncogene. 2011;30(9):1020-1031.

66. El-Balat A, Schmeil I, Karn T, et al. TFF3 expression as stratification marker in borderline epithelial tumors of the ovary. Pathol Oncol Res. 2018;24(2):277-282. doi:10.1007/s12253-017-0240-4

67. Köbel M, Xu H, Bourne PA, et al. IGF2BP3 (IMP3) expression is a marker of unfavorable prognosis in ovarian carcinoma of clear cell subtype. Mod Pathol. 2009;22(3):469-475. doi:10.1038/modpathol.2008.206

68. El-Balat A, Sanger N, Karn T, et al. IMP3 expression in borderline tumors of the ovary. Anticancer Res. 2017;37(2):583-588 doi:10.21873/anticanres.11351

69. Szkandera J, Kiesslich T, Haybaeck J, Gerger A, Pichler M. Hedgehog signaling pathway in ovarian cancer. Int $J \mathrm{Mol} S \mathrm{Sci}$. 2013;14(1):1179-1196. doi:10.3390/ijms14011179

70. Bhattacharya R, Kwon J, Ali B, et al. Role of hedgehog signaling in ovarian cancer. Clin Cancer Res. 2008;14(23):7659-7666. doi:10.1158/1078-0432.CCR-08-1414

71. Liao X, Siu MK, Au CW, et al. Aberrant activation of hedgehog signaling pathway in ovarian cancers: effect on prognosis, cell invasion and differentiation. Carcinogenesis. 2009;30(1):131-140. doi:10.1093/carcin/bgn230
72. Schmid S, Bieber M, Zhang F, et al. Wnt and hedgehog gene pathway expression in serous ovarian cancer. Int J Gynecol Cancer. 2011;21 (6):975-980. doi:10.1097/IGC.0b013e31821caa6f

73. Ciucci A, De Stefano I, Vellone VG, et al. Expression of the glioma-associated oncogene homolog 1 (gli1) in advanced serous ovarian cancer is associated with unfavorable overall survival. PLoS One. 2013;8(3):e60145. doi:10.1371/journal.pone.0060145

74. Chen X, Horiuchi A, Kikuchi N, et al. Hedgehog signal pathway is activated in ovarian carcinomas, correlating with cell proliferation: it's inhibition leads to growth suppression and apoptosis. Cancer Sci. 2007;98(1):68-76. doi:10.1111/j.1349-7006.2006.00353.x

75. Ozretic P, Trnski D, Musani V, et al. Non-canonical Hedgehog signaling activation in ovarian borderline tumors and ovarian carcinomas. Int J Oncol. 2017;51(6):1869-1877. doi:10.3892/ijo.2017.4156

76. Song X, Yan L, Lu C, et al. Activation of hedgehog signaling and its association with cisplatin resistance in ovarian epithelial tumors. Oncol Lett. 2018;15(4):5569-5576. doi:10.3892/ol.2018. 8008

77. Kanter M, Turan G, Usta C, et al. Survivin and cycline D1 expressions are associated with malignant potential in mucinous ovarian neoplasms. J Mol Histol. 2016;47(2):145-152. doi:10.1007/s10735-016-9661-8

78. Aksamitiene E, Kiyatkin A, Kholodenko BN. Cross-talk between mitogenic Ras/MAPK and survival PI3K/Akt pathways: a fine balance. Biochem Soc Trans. 2012;40(1):139-146. doi:10.1042/ BST20110609

79. Jacobs I, Oram D, Fairbanks J, Turner J, Frost C, Grudzinskas JG. A risk of malignancy index incorporating CA 125, ultrasound and menopausal status for the accurate preoperative diagnosis of ovarian cancer. Br J Obstet Gynaecol. 1990;97(10):922-929. doi:10.1111/ j.1471-0528.1990.tb02448.x

80. Tingulstad S, Hagen B, Skjeldestad FE, et al. Evaluation of a risk of malignancy index based on serum CA125, ultrasound findings and menopausal status in the pre-operative diagnosis of pelvic masses. $\mathrm{Br}$ $J$ Obstet Gynaecol. 1996;103(8):826-831. doi:10.1111/j.14710528.1996.tb09882.x

81. Tingulstad S, Hagen B, Skjeldestad FE, Halvorsen T, Nustad K, Onsrud M. The risk-of-malignancy index to evaluate potential ovarian cancers in local hospitals. Obstet Gynecol. 1999;93(3):448-452. doi:10.1097/00006250-199903000-00028

82. Yamamoto Y, Yamada R, Oguri H, Maeda N, Fukaya T. Comparison of four malignancy risk indices in the preoperative evaluation of patients with pelvic masses. Eur J Obstet Gynecol Reprod Biol. 2009;144(2):163-167. doi:10.1016/j.ejogrb.2009.02.048
Cancer Management and Research

\section{Publish your work in this journal}

Cancer Management and Research is an international, peer-reviewed open access journal focusing on cancer research and the optimal use of preventative and integrated treatment interventions to achieve improved outcomes, enhanced survival and quality of life for the cancer patient.
The manuscript management system is completely online and includes a very quick and fair peer-review system, which is all easy to use. Visit http://www.dovepress.com/testimonials.php to read real quotes from published authors. 